\title{
EL DOGMA DE LA COMPETITIVIDAD FRENTE A LA UTOPÍA DE LA SUSTENTABILIDAD: ANÁLISIS CRÍTICO DEL ETHOS DESARROLLISTA Y ECONOMICISTA*
}

Recibido: 05 de octubre de 2015 - Aprobado: 26 de agosto de 2016

DOI: DOI: 10.22395/seec.v19n41a7

Fredy Alfonso Ochoa Fonseca**

\section{RESUMEN}

A través del análisis de discursos y la dialéctica, este artículo tiene como objetivo argumentar de manera crítica el ethos que orienta la apuesta por la competitividad. Se encuentra que como dogma, fruto de una sociedad mercantilizada y de una visión economizada del mundo y de la vida, la competitividad desconoce las bases epistemológicas de la economía, pone todas las apuestas bajo la óptica de la maximización del beneficio y el aumento de la rentabilidad, no tiene en cuenta la ética, confunde valor con precio, y se ha extendido a todas las áreas de la sociedad poniendo en peligro de diversidad biológica y cultural. En contraste al dogma, se presentan alternativas emergentes a la competitividad, como la cooperación y la colaboración, enmarcadas dentro de los nuevos caminos más allá del desarrollo, como el buen vivir las epistemologías del Sur, el poscapitalismo y la sustentabilidad.

\section{PALABRAS CLAVE}

Competitividad, sustentabilidad, desarrollo económico, colaboración

\section{CLASIFICACIÓN JEL}

\author{
Q01, O10
}

\section{CONTENIDO}

Introducción; 1. El imperativo de la competitividad; 2. De la competitividad entre empresas a la competitividad entre naciones y territorios, el evangelio Porter; 3. Sustentabilidad y competitividad; 4. Las utopías; 5. Conclusiones; Bibliografía.

Este artículo de investigación se escribe gracias al apoyo de Conacyt y Ecosur, México y a la tesis titulada "Ecoturismo y la vida cotidiana de las familias en Lacanjá Chansayab", para optar al título de doctor en Ciencias de la Ecología y el Desarrollo Sustentable, Departamento Agricultura, Sociedad y Ambiente, del Colegio de la Frontera Sur - Ecosur, México, bajo la supervisión del Dr. Eduardo Bello.

** Diseñador industrial, Universidad Nacional de Colombia, Bogotá, Colombia. Magíster en Medio Ambiente y Desarrollo, Universidad Nacional de Colombia, Bogotá, Colombia. Estudiante del doctorado en Ciencias de la Ecología y el Desarrollo Sustentable, Ecosur, México. Docente Investigador, Universidad Externado de Colombia, Bogotá, Colombia. Correo electrónico: fredyochoa@gmail.com o faochoa@ ecosur.edu.mx 


\title{
COMPETITIVENESS DOGMA CONCERNING THE SUSTAINABILITY UTOPIA: CRITICAL ANALYSIS OF THE DEVELOPMENTALIST AND ECONOMISTIC ETHOS
}

\begin{abstract}
By analyzing discourses and dialects, this article aims to argue, in a critical manner the ethos that orients the bet on competitiveness. A dogma is found as fruit of a merchant society and, in a economized vision of the world and of life, competitiveness in not aware of the epistemological bases of the economy, sets all the bets under the profit maximization scope and profit increase, doesn't bare in mind ethics, confuses value with price, has extended to all areas of society jeopardizing biological and cultural diversity. In contrast to the dogma, emerging strategies arise that challenge competitiveness, such as cooperation and collaboration, framed within the new paths that go further than development. For good-living, epistemologies from the south, post capitalism and sustainability.
\end{abstract}

\section{KEY WORDS}

Competitiveness, sustainability, economic development, collaboration

\section{CLASIFICACIÓN JEL}

$\mathrm{Q} 01,010$

\section{CONTENIDO}

Introduction; 1. Competitiveness imperative; 2. Competitiveness between companies, nations and territories, the Porter gospel. 3. Sustainability and competitiveness 4. Utopias; 5. Conclusions; Bibliography.

\section{O DOGMA DA COMPETITIVIDADE FRENTE À UTOPIA DA SUSTENTABILIDADE: ANÁLISE CRÍTICO DO ETHOS DESENVOLVISTA E ECONOMICISTA}

\section{RESUMO}

Através da análise de discursos e a dialética, este artigo tem como objetivo argumentar de maneira crítica o ethos que orienta a aposta pela competitividade. Se encontra que como dogma fruto de uma sociedade mercantilizada e, de uma visão economizada do mundo e da vida, a competitividade desconhece as bases epistemológicas da economia, põe todas as apostas sob a ótica da maximização do beneficio e o aumento da rentabilidade, não tem em conta a ética, confunde valor com preço, se há estendido a todas as áreas da sociedade pondo em perigo de diversidade biológica e cultural. Em contraste ao dogma, se apresentam alternativas emergentes à competitividade, como a cooperação e a colaboração, demarcadas dentro dos novos caminhos mais além do desenvolvimento, como o bom viver as epistemologias do sul, o pós-capitalismo e a sustentabilidade.

\section{PALAVRAS CHAVE}

Competitividade, sustentabilidade, desenvolvimento econômico, colaboração

\section{CLASSIFICAÇÃO JEL}

$\mathrm{Q} 01,010$

\section{CONTEÚDO}

Introdução; 1. O imperativo da competitividade; 2. Da competitividade entre empresas à competitividade entre nações e territórios, o evangelho Porter; 3. Sustentabilidade e competitividade; 4. As utopias; 5 . Conclusões; Bibliografia. 


\section{INTRODUCCIÓN}

Como parte de la imposición de un modelo neocapitalista estadounidense, el cual tuvo como fin ampliar su mercado, la competitividad es hoy un imperativo no solo para las empresas sino también para los territorios. Como se verá más adelante, basta con leer documentos colombianos de planificación de desarrollo nacionales, departamentales y municipales, para encontrar que la competitividad se ha convertido en la receta para los males de la sociedad y el remedio para el subdesarrollo.

En efecto, autores como Escobar (1998), Esteva (1996) y Leff (2002), argumentan que como legado de la Modernidad y el pensamiento occidental, a partir de $1950 \mathrm{el}$ desarrollo se convirtió en la meta social, y desde la década de 1990 la sostenibilidad se hizo el sueño. Hoy, la competitividad es el requisito e indicador del desarrollo y de la sostenibilidad, como lo muestra el Global Competitive Report, Schwab (2014).

Bajo la metodología de análisis del discurso de Foucault (1999), y usando como referencia las críticas al desarrollo y la competitividad de Escobar (1998), Esteva (1996), Leff (2001), Gudynas (2004, 2011), Aktouf (2008), Krugman (1994), entre otros, el presente artículo parte de la dialéctica en torno a la competitividad como un dogma, fruto de una sociedad mercantilizada, dominada por el neoliberalismo y una visión economizada del mundo y de la vida, Sandel (2014), Gudynas (2011), Leff (2001).

Como resultado se encuentra que la competitividad, desconoce las bases epistemológicas de la economía, Aktouf (2008); pone todas las apuestas bajo la óptica de la maximización del beneficio y el aumento de la rentabilidad Gudynas (2004), y que, al igual que el mercado, no tiene en cuenta la ética, Beschorner (2013). Asimismo, confunde valor con precio, el hacer las cosas bien con ser competitivo y se ha extendido a todas las áreas de la sociedad, educación, cultura, sostenibilidad, etc. La competitividad, al igual que el desarrollo, es hoy incuestionable, se constituye así en un dogma que representa un peligro para la diversidad biológica y cultural, para la sustentabilidad.

Por último, a partir de la biología, la ecología y la antropología, se presentan alternativas emergentes a la competitividad, como la cooperación y la colaboración por Ruiz-García (2013) y otros, la economía del compartir de Mason (2015), enmarcadas dentro de los nuevos caminos más allá del desarrollo, como el buen vivir descrito por Gudynas (2011), las epistemologías del Sur propuestas por De Sousa (2011), y la sustentabilidad de autores como Leff (2001), Carrizosa (2002) y Ángel y Ángel (2002), alternativas y caminos que, según Riechmann (2014), son catalogados como utópicos. 


\section{EL IMPERATIVO DE LA COMPETITIVIDAD}

El Plan Nacional de Desarrollo 2014-2018 menciona 16 veces la palabra competitividad y 11 la sostenibilidad; esta última haciendo referencia a mantener el sistema, DNP (2015). Además, el Plan define la competitividad como su primera estrategia transversal y regional, DNP (2015). Es decir, que no importa si se habla de salud, educación, agricultura, turismo, paz, ambiente, reducción de la pobreza o áreas protegidas, la competitividad es la apuesta y requisito común. Asimismo, el documento muestra un diagnóstico de Colombia igual al de 1950, esto es, subdesarrollo, pobreza, falta de educación e industrialización, Escobar (1998), la diferencia es que ahora se le agrega la falta de competitividad, DNP (2015).

Sin embargo, el caso de este documento de política no es el único. Desde la década de 1990, los planes nacionales, departamentales y municipales de desarrollo y de turismo han hecho de la competitividad el camino y la meta; así, por ejemplo, según el DNP (2007, p. 25):

La competitividad se logra a partir de dos grandes transformaciones: el desarrollo del capital humano y del capital físico. La educación, la investigación, la aplicación de conocimientos, el capital físico y el humano, el crédito popular y el apoyo al emprendimiento son los pilares de la competitividad para aumentar el ingreso y mejorar su distribución.

Pero ¿de dónde viene la competitividad?, ¿se trata del nuevo paradigma de progreso que surge bajo la mirada mercantil y reduccionista de la Modernidad?

Como parte del legado de la Modernidad y de Occidente, el mercado y la economía se convirtieron en el instrumento e indicador de progreso y desarrollo. Por este camino y sin darse cuenta, la humanidad pasó de una economía de mercados a ser lo que Sandel (2014) denomina una sociedad de mercados, pues esta forma de entender al mundo se apoderó de todos los aspectos de la vida: la familia, el civismo, la salud, la educación, el ambiente, la política, los medios y la ley.

Ligado a lo anterior, la visión más difundida sobre desarrollo corresponde a la de crecimiento económico, visión que se convierte en pilar de la vida social moderna, pero que desconoce los límites físicos, ecológicos y geológicos del planeta como lo sostienen Leff (2004); Escobar (1998); Max-Neef (1994); Eschenhagen y Maldonado (2014). Es de anotar que conceptos como desarrollo sostenible y desarrollo humano sostenible, que incorporan criterios ambientales y sociales, son también cuestionados de manera amplia por varios autores como los anteriormente mencionados, para quienes se trata de nuevos eufemismos que siguen siendo antropocéntricos y economicistas. 
Es decir, con conceptos de desarrollo en los que los seres humanos se configuran en el centro de toda la existencia y, por lo tanto, la naturaleza, reducida al término "ambiente", tiende a ser percibida de manera utilitaria al servicio de las necesidades de estos. La relación humano-naturaleza es, por tanto, de tipo mercantil; de allí que la preocupación del desarrollo sostenible sea solo por los recursos naturales. Esto trae como consecuencia, el asumir que los seres humanos tienen el "derecho" a usar estos recursos incluso hasta su destrucción y que el mercado es el mejor criterio para su manejo. En palabras de Esteva (2014), el desarrollo fue la estrategia que transformó a la gente en hombres económicos.

Este sesgo mercantil avanzó sobre casi todas las esferas de la vida; sus conceptos y términos invadieron desapercibidamente el lenguaje cotidiano. En las empresas, los humanos se convirtieron en recurso o capital. Gudynas (2004) afirma que es también usual que los gobernantes se refieran a propuestas educativas, ambientales y sociales en términos de oferta, consumidor, producto, e incluso, políticos que durante la campaña electoral se presentan como gerentes que administrarán de forma eficiente el país o la ciudad, como si se tratara de empresas. Así, por ejemplo, Enrique Peñalosa en la campaña a la alcaldía de Bogotá en 2015.

Bajo esta mirada, como lo sostienen Gudynas (2004), y Daly y Cobb (1997), se asume que el mercado es el único medio para la asignación eficiente de los recursos, por lo que no es necesario que las personas discutan cuáles son las metas de calidad de vida a las que aspiran, ni cuáles son las tasas de aprovechamiento más sostenibles de los recursos naturales

Según esta mirada, el orden del mercado resulta de la competencia entre los individuos; son estos, persiguiendo sus propios intereses y beneficios quienes determinan la marcha de la sociedad, Hayek, 1968, citado en Gudynas (2004). Esto porque, en la concepción de Adam Smith, el hombre solo recibirá benevolencia de otros, si esta representa para ellos un beneficio para su propio interés; no se invocan necesidades, sino sus ventajas y el bien común se logra cuando se busca la ganancia propia, agrega Gudynas (2004).

Se privilegia, por tanto, el individualismo frente a las acciones colectivas, no solo en la posesión, también desde la competencia, la determinación del precio resulta de la lucha entre las personas (jurídicas en la actualidad), por lo que se rechaza la intromisión del Estado o de cualquier otro agente en el mercado y la planificación del devenir de la sociedad, porque serían ataques a la libertad personal y de competir, Gudynas (2004).

Bajo este marco, no hay lugar para la ética de la solidaridad o el altruismo, se les califica de utopías antinaturales, con el argumento de que las personas son 
egoístas por naturaleza, Gudynas (2004). Tampoco hay lugar para otras formas de relación que no sean la lucha y la competencia, como la reciprocidad, el trueque, el canje o la colaboración.

Lo anterior está ligado con el darwinismo económico, denominado así porque para esta postura la evolución es el resultado exclusivo de la lucha entre especies e individuos, y la supervivencia del más fuerte. De esta manera se legitima la competencia como parte esencial de la evolución, es la respuesta natural al cambio que garantiza la eficacia. De allí surgen frases ya popularizadas como "el pez grande se come al chico", haciendo alusión a la supervivencia de la empresa más fuerte; "lucha o muere, compite o muere", o que se hable de procesos de "fortalecimiento empresarial" con el fin de ser más competitivos.

Bajo esta visión mercantil, la racionalidad economicista, y no la ética, se constituye en la fuente de preceptos y principios morales de interpretación social; son las relaciones de mercado, la libre empresa y la libre competencia las que garantizan los derechos de los individuos y su propiedad, pasando por encima de conceptos filosóficos, como el bien público o el bien común, Gudynas (2004).

Esta mercantilización de la sociedad y de la vida, la búsqueda del crecimiento económico infinito, acompañada de la carrera hacia la ventaja competitiva, se convirtieron en un dogma, una estructura de pensamiento y acción en casi todos los ámbitos, incluso en la gobernanza y en la política económica de naciones y territorios, Aktouf (2008).

Hoy, la doctrina de la competitividad, como la denomina Krugman (1994), es común en todas las áreas de la sociedad y con su paso ha convertido a la humanidad en "individuos consumistas y competitivos", como lo plantea Escobar (2014, p. 55). Según Escobar (2014, p. 21):

Las luchas por defender paisajes, montañas, bosques, semillas, ríos, territorios, páramos; $y$, por supuesto, otras formas humanas de construir el mundo son testimonios elocuentes de la crisis del Mundo-Uno: moderno/capitalista, secular, racional y liberal con su insistencia en la ilusión del "progreso" y el "desarrollo", en el que el consumo individual y la competitividad del mercado se convierten en la norma y medida del actuar humano.

Así, por ejemplo, el afán de la competitividad en la educación no se limitó a la formación por competencias; hoy, las formas de medición académica se basan en la productividad que busca la rentabilidad, en lo que Lander (2005) llama un mercado de la ciencia. Esto se expresa en la lucha por la acumulación de citas por parte de autores, revistas y grupos de investigación, con el fin de ser más competitivos. 
Otro ejemplo es el del Ministerio de Educación Nacional (MEN) de Colombia, que en la búsqueda de la competitividad de las instituciones universitarias creó el MIDE, que permite hacer un escalafón de la excelencia académica e incluye, como uno de sus indicadores, la capacidad que tiene la universidad de generar sus propios recursos económicos'. Esto genera algunos cuestionamientos ¿Por qué incentivar la competencia entre universidades? ¿Qué tiene que ver la rentabilidad con la excelencia académica? ¿La universidad es una empresa y la educación un sector económico en búsqueda de la rentabilidad?

Este modo de ver y entender el mundo puso a todos a competir, no solo entre empresas, también entre naciones, regiones, municipios, personas, ecosistemas y áreas protegidas, con el único fin de maximizar el beneficio y la rentabilidad. Como sucedió con el desarrollo, la competitividad se convirtió en el ingrediente ineludible e incuestionable para un mundo mejor, ingrediente sin sabor ni fondo, ingrediente vacío, pero clave en la jerga de los expertos.

\section{DE LA COMPETITIVIDAD ENTRE EMPRESAS A LA COMPETITIVIDAD ENTRE NACIONES Y TERRITORIOS, EL EVANGELIO PORTER}

Las comparaciones empresa-nación, con afirmaciones del tipo: "Colombia debe ser competitiva en el mercado mundial, tal como Ecopetrol lo es", se convirtieron en acríticas e incuestionables. Sin embargo, como afirma Krugman (1994), definir la competitividad de una nación o un territorio no es tan sencillo como con una empresa. Añade Krugman que en el caso de una empresa es fácil establecer el punto de equilibrio y el ser capaz de cubrir sus gastos y costos para mantenerse en el mercado. No obstante, en el caso de las naciones y los territorios, estos no quiebran, tampoco desaparecen como las empresas, pueden ser felices o infelices, pero no tienen un punto de equilibrio bien definido, Krugman (1994).

Krugman (1994) agrega que los países no compiten entre sí, como lo hacen las corporaciones. Mientras las ventas de una corporación se centran casi en su totalidad en las personas que no trabajan allí, en el caso de un país, prima el comercio nacional. Asimismo, en el caso del comercio internacional, dos países que producen el mismo tipo de producto son competencia y, a la vez, son mercados de exportación para otros productos; la productividad de un país no hace menos productivo a otro, Krugman (1994).

Al respecto Aktouf (2008, p. 171) plantea el cuestionamiento: "Las naciones y los Estados, y sus políticas económicas, ¿̇pueden ponerse sobre el mismo plano, institucional, intelectual,

Una descripción detallada de las características del MIDe se pueden consultar en: MEN -Ministerio de Educación Nacional- (2015). Modelo MIDE. 
ética, moral, social y político, que una firma o una empresa, cualquiera que ella sea?". En efecto, los objetivos de los Estados, las naciones y los territorios no puede ser reducidos a la búsqueda de ventajas, ganancias, beneficios, rentabilidad, bajo el manto de la eficacia estratégica, concebida en exclusivo en términos monetarios y financieros.

Yendo a los orígenes, si bien la competitividad de las naciones fue estudiada por Adam Smith con la ventaja absoluta y David Ricardo con la ventaja comparativa, la metáfora de que cada nación es como una gran corporación compitiendo en el mercado global data de las décadas de 1980 y 1990, Krugman (1994, p. 18).

Durante la década de 1990, frente al temor de los Estados a ser dejados fuera de la carrera de la globalización económica y con el fin de ser congruentes con la demanda del mercado mundial, la competitividad se plantea como parte del último ethos desarrollista, el neoliberal, Esteva (2014). De esta manera la doctrina de la competitividad ligada al desarrollo, se hace persuasiva entre los líderes de opinión del mundo; se convierte en la respuesta a las preguntas y el diagnóstico a los problemas sobre el desempleo y la economía, Krugman (1994).

Es en las décadas de 1980 y 1990 cuando surge el porterismo con su pensamiento estratégico, al cual se le debe según Aktouf (2008), el llevar las naciones hacia la carrera por la ventaja competitiva, utilizando los instrumentos e indicadores creados para las empresas.

A Porter se le califica como el padre intelectual de los especialistas en estrategia, Aktouf (2008). Asimismo, se le llama el "gurú" de la estrategia y la competitividad, no solo de las corporaciones, también de las naciones.

Su obra inicia con el artículo How Competitive Forces Shape Strategy en la Harvard Business Review, Porter (1979), la cual se constituye en la base para sus siguientes publicaciones: Competitive Strategy: Techniques for Analyzing Industries and Competitors, Porter (1980); Competitive Advantage: Creating and Sustaining Superior Performance, Porter (1985), entre otras.

Sobre estas publicaciones cabe anotar que su conocimiento empresarial es desde "fuera", puesto que Porter no ha sido empresario. Lo que hace es escoger un grupo de corporaciones para hacer estudios de casos a posteriori, selecciona ciertas variables financieras, para excluir otras de carácter social y ambiental, que repercuten en el éxito empresarial. Además, el único objetivo de su enfoque estratégico es el triunfo de las empresas entendido como el incremento en la rentabilidad, sin importar efectos, como el despido de empleados o la contaminación. De esta manera prioriza el nombre de la empresa y su rentabilidad, frente a la razón social de la misma. 
Luego de publicaciones enfocadas en empresas, pero utilizando las mismas bases, Porter da un salto a la gobernanza con The Competitive Advantage of Nations, Porter (1990). Posteriormente, Porter y Kramer (2011), con el artículo Creating Shared Value, plantean la creación de valor compartido como estrategia para empresas y territorios.

De esta forma, el porterismo, sin bases epistemológicas ni metodológicas válidas, pasó de un decálogo de normas para administradores, a ser un marco generalizado de concepción y de análisis, una visión del mundo, una ideología para la gobernanza, según Aktouf (2008). Para el porterismo, los Estados y las sociedades humanas son vistas como conglomerados de negocios (Clusters), dedicados al servicio de multiplicar el dinero, en otras palabras, la rentabilidad, como plantea Aktouf (2008).

Porter (1990) basa toda su teoría de la ventaja competitiva de las naciones, sobre estudios de caso, de industrias específicas de diez países; de acuerdo con Aktouf (2008). De esta forma, a partir del análisis ex post de un número limitado de grandes industrias de ciertos sectores en países desarrollados, Porter (1990) asume que entiende toda la economía, como si acumular estudios de casos se convirtiera en conocimiento científico y como si las naciones fueran iguales a las industrias según Aktouf (2008), y desconociendo, además, los principios de la teoría general de sistemas de von Bertalanffy (1969) y de los sistemas complejos de Gunderson y Holling (2002).

Aktouf (2008) afirma que, a pesar de que su obra completa se enfoca en la competitividad y el valor, el propio Porter reconoce que no existe ninguna teoría para explicarla que sea muy aceptada, y por tanto en ninguno de sus libros y artículos incluye definiciones satisfactorias para estos dos conceptos.

Sin teorías ni definiciones, el dogma porteriano pregona la competitividad generalizada y la carrera hacia las ventajas competitivas, inscritas en la rivalidad, el egoísmo, la inmediatez, la despreocupación e, incluso, la crítica a la búsqueda del bienestar mutuo y el comercio justo, sin importar que la conquista de dichas ventajas vaya en contra de los intereses de la sociedad, de sectores de la economía nacional e, incluso, en contra de los países con los cuales se comercia Aktouf (2008).

Respecto a epistemología, Porter desconoce las diferencias aristotélicas entre economía y crematística ${ }^{2}$, entre el mundo económico-monetario que es concebido como infinito y el mundo físico que se caracteriza por la finitud de sus recursos, de acuerdon con Aktouf (2008). La ventaja competitiva de Porter obedece a la ideología

2 Arte de hacerse rico o de la maximización de la acumulación de dinero por los individuos, MartínezAlier y Schlüpmann (1991); Daly (2010). 
rentabilista e inmediatista de maximización del beneficio, es decir, la crematística que caracteriza al capitalismo de tipo financiero o multinacional (Aktouf, 2008). Porter, incluso, desconoce que la teoría detrás de las ventajas comparadas se basa en un espíritu de complementariedad y de cooperación, nunca de beligerancia comercial, según Aktouf (2008).

Relacionado con lo anterior, Porter, al igual que la economía ortodoxa, plantea de manera implícita que la acumulación y la producción de riqueza, así como el crecimiento económico pueden ser infinitos. Ignora de esta forma las preocupaciones sobre los límites del crecimiento reconocidos desde hace 40 años que dieron origen al desarrollo sostenible.

Porter insiste en plantear que miles de millones de personas compitan unas con otras, para alcanzar el crecimiento máximo y los niveles de vida similares a los de los más ricos, con los volúmenes de consumo que esto implica, en un planeta cuyos recursos son limitados, siguiendo a Aktouf (2008).

Porter también desconoce la economía ecológica, que se basa no en el análisis de flujos de dinero, sino de la transformación de la energía, el agua y el carbono, como lo plantean Daly y Cobb (1997), economía que hace fuertes críticas al uso del PIB macroeconómico como indicador, pues nada dice sobre equidad, justicia o sustentabilidad.

La administración y la gobernanza bajo ese enfoque son un ejercicio de la Modernidad, de la visión mecanicista que en este caso entiende a la sociedad, a las personas y a las naciones, como máquinas, llamadas empresas. Lo importante es entonces, la persona jurídica, la agencia, la corporación. En síntesis, la organización, que dejó de ser adjetivo, para convertirse en sujeto, haciendo del medio, el objetivo. La visión pasa de ser antropocéntrica, para ser organocéntrica, centrada en las organizaciones. El DNP (1995, p. 8) plantea que:

... venimos hoy a constituir aquí una empresa, la más ambiciosa e importante empresa, la empresa del desarrollo social y la competitividad económica. De esa formidable empresa, la empresa de la Colombia del siglo XXI, serán socios todos los colombianos, sin distingos de origen, sexo, raza o religión.

Por ese camino, la constitución de empresas se convirtió en requisito para que las comunidades de base accedan a servicios sociales. Las personas (de carne y hueso) ya no son actores o interlocutores válidos, se necesita del órgano llamado empresa para que lo sean.

La empresa es también un imperativo, se llega al extremo reduccionista de afirmar que solo las empresas crean valor. A esto se suma que los derechos de la 
organización se pusieron por encima de los de las personas y los Estados, entre otras razones por lo que se denomina el derecho a la libre competencia, de allí casos en los que la Organización Mundial de Comercio (OMC) tercia a favor de las empresas a costa de los intereses y derechos ambientales y sociales, de comunidades locales y Estados.

También como herencia de lo que Leff (2001) llama la Modernidad y la racionalidad científica, Porter (1990), en lugar de integrar, segmenta, divide la gestión estratégica en los bienes y la forma en que estos se administran. Separa la relación: una es ventaja comparativa, y a la otra la llama ventaja competitiva.

Esta separación aprovecha la perspectiva del capitalismo señalada por Gudynas (2015) en la que es más importante el control de las redes de comercialización y producción, que el control sobre la propiedad de los recursos. La ventaja competitiva de Porter está dada en la producción y comercialización, de forma que se enfoca en una fase en la que no se tiene que negociar con comunidades por el acceso y los costos de los recursos, ni preocuparse por los efectos ambientales de su extracción.

Con la teoría de creación de valor compartido (CVC) Porter y Kramer (2011), se equivocan de nuevo, y asumen que el comercio justo busca el aumento de la rentabilidad, cuando este no busca aumentar la rentabilidad y los ingresos en un sector, sino la justicia en la distribución de ingresos y de beneficios no monetarios.

Con la CVC, Porter y Kramer (2011), otra vez es pretensioso, se ufanan de reinventar el capitalismo, mientras mantienen el paradigma del crecimiento infinito, con un enfoque en necesidades que obedece a la economía neoclásica. Para Beschorner (2013), con la CVC, Porter reitera de manera implícita que los actores corporativos cumplen un papel en la gobernanza, en un triángulo mercado, Estado y sociedad civil, tal y como lo hizo con las cadenas de valor.

Sin el mínimo asomo de ética, Porter y Kramer (2011) afirman, que la filantropía es errada pues socava el éxito empresarial, que la responsabilidad social empresarial (RSE) es filantropía y que la CVC es hacer dinero a partir de las necesidades de la sociedad. Además, critican la RSE porque en ella valor significa hacer el bien, por eso en su propuesta de CVC, valor significa beneficios económicos y sociales en relación a los costos. Porter reitera, por tanto, su confusión entre valor y precio, a lo que suma que el precio y la rentabilidad son más importantes que hacer el bien.

Porter y Kramer (2011) continúan su crítica a la RSE, indican que mientras esta se interesa por la ciudadanía, la filantropía y la sustentabilidad, la CVC busca la creación 
de valor conjunta entre la empresa y la comunidad, y ya se explicó a qué llama valor Porter. Cuestionan la RSE porque es ajena a la maximización de la rentabilidad; está orientada hacia factores externos, no busca la competitividad y tiene un impacto limitado en las utilidades de la empresa.

De nuevo recurre al análisis ex post de grandes empresas, y como en el caso de sus demás publicaciones, presenta cifras y hace afirmaciones sin explicar la metodología para su obtención. Su ciencia es entonces, tomar las estrategias de un grupo de grandes corporaciones para alcanzar el éxito en el mercado y ponerles un nuevo nombre: ventaja competitiva, cadena de valor o creación de valor compartido, publicarlas en artículos y libros de la universidad en la que trabaja, sin revisión, sin citas, sin metodología.

La manera porteriana de entender al mundo y la economía se expande rápido por el planeta, arraigándose en las conciencias y las enseñanzas. Hoy en las escuelas de administración, Porter es materia obligada del pensamiento estratégico, como argumenta Aktouf (2008), cerrando la oportunidad a otras posturas y planteamientos. Facultades y gobiernos reciben de manera acrítica su nuevo "evangelio". Cabe mencionar que en el caso colombiano Porter ha asesorado directamente al Gobierno y a agremiaciones; así por ejemplo, su intervención en 2006 llevó a la creación del Sistema Nacional de Competitividad e Innovación. Según Colvin (2012), "Él (Michel Porter) ha influido más ejecutivos y más naciones que cualquier otro profesor en la Tierra. Ahora a los 65 años de edad, él y todo su equipo estrella tienen como objetivo rescatar la economía de los Estados Unidos".

Esta cita permite plantear los interrogantes: ¿En qué consiste ese rescate de la economía? ¿A costa de qué y de quiénes se hará? Un indicio de la respuesta se encuentra en la salud, que bajo el neoliberalismo, y con el fin de hacerlo un sector competitivo, se convirtió en un servicio prestado por empresas privadas. Hoy los Estados usan recursos públicos (es decir, de la gente) para "salvar" estas empresas, además de limitar el acceso a medicamentos y tratamientos que no sean rentables. Por su parte, las empresas de salud, en su afán por ser más competitivas, recurren a estrategias porterianas como la integración vertical y horizontal, la disminución de honorarios a su personal, y la subcontratación.

De esta manera el "evangelio" se resume en una doctrina por la dominación del otro llamada competitividad; este es el dogma que incentiva la rivalidad y la lucha desde lo local hasta lo global, reguladas por el libre mercado que es transparente y justo. En esta lucha, al igual que en la evolución, como es natural, solo el más fuerte sobrevivirá. 


\section{SUSTENTABILIDAD Y COMPETITIVIDAD}

A partir de los años noventa, las preocupaciones por el futuro de la humanidad, su calidad de vida, la pobreza, la inequidad, la pérdida de las culturas, de la cobertura boscosa, la biodiversidad y de los recursos naturales, se juntaron bajo un sueño llamado sostenibilidad, lo que llevó, como afirma Leff (2001), a que este concepto se hiciera fundamental en los discursos del desarrollo, pero ahora con tres pilares: ambiental, sociocultural y económico. No era para menos, pues, como se verá de manera breve, estas preocupaciones están sustentadas por cifras e instituciones.

Desde el pilar ambiental, hoy se reconoce que el cambio climático es el principal problema de nuestro tiempo. El Intergovernmental Panel on Climate Change (IPCC, 2015, p. 2) afirma que la influencia humana en el sistema climático es clara: las recientes emisiones antropogénicas de gases efecto invernadero son las más altas de la historia y los cambios climáticos han ampliado sus impactos en los sistemas naturales y, por ende, en los humanos.

De igual forma, según el IPCC (2015) el calentamiento global es indiscutible; desde 1950 se han observado cambios sin precedentes. La atmósfera y el océano se han calentado, el hielo en los polos y cumbres nevadas ha disminuido y el nivel del mar ha aumentado. La industrialización, los procesos de globalización, los modelos de consumo, el aumento en el tamaño de las ciudades y el incremento de la población humana son las las causas principales del cambio climático Millennium Ecosystem Assessment (2005).

Estas causas junto con el cambio climático, son, a su vez, los mayores responsables de la pérdida de biodiversidad, reconocida también como otro gran problema ambiental de nuestro tiempo (Millennium Ecosystem Assessment, 2005). Cambio climático y pérdida de biodiversidad ponen en riesgo el futuro no solo humano, sino de la vida en la Tierra.

Pero no son solo problemáticas ambientales. Respecto al pilar económico y la pobreza, el Banco Mundial (2011) estima que el 17 \% de la población del mundo (1.300 millones de personas) vive con menos de US\$1,25. Asimismo, la Oxfam (2014) en sus estudios sobre equidad y justicia en la distribución, afirma que la riqueza mundial está dividida en dos: casi la mitad está en manos del $1 \%$ más rico de la población, y la otra mitad se reparte entre el $99 \%$ restante.

En aspectos culturales, solo por poner un ejemplo, según la Unesco (2003) alrededor del $96 \%$ de las lenguas del mundo son habladas por un aproximado del $3 \%$ de los habitantes del mundo; muchas de estas lenguas están en peligro de desaparecer; lo mismo sucede con el patrimonio cultural material e inmaterial. 
Frente a estas preocupaciones, la competitividad aparece de nuevo. Hoy no solo orienta los documentos de planificación y política de los países, como se mencionó, es también el indicador de desarrollo sostenible base para la toma de decisiones estatales.

No es exagerado decir que en la actualidad hasta a los ecosistemas se les exige ser competitivos. A través del pago por servicios ecosistémicos se convirtieron funciones de los ecosistemas en servicios, dándoles un valor de uso, que posteriormente se convierte en valor de cambio, para así poder insertarlos en el mercado. ¿Cuál ecosistema captura más CO²? ¿Cuál ofrece más servicios ecosistémicos? ¿Es más rentable el servicio ecosistémico que brinda cierta área protegida o la obra que la destruirá? Lo mismo sucede con la economía de la cultura que pone bajo las reglas del mercado y la competitividad las fiestas, las tradiciones, el patrimonio inmaterial y material.

¿Cómo pudo avanzar el dogma de la competitividad para afirmar que el camino hacia el desarrollo sostenible pasa por las luchas y la rivalidad entre culturas y ecosistemas? Si en efecto el desarrollo sostenible se mide en términos de competitividad, es decir, en función de la rentabilidad, del precio y de las reglas del mercado, sufrirá los mismos males que cualquier empresa o producto; si la estrategia no es rentable, lo que se intenta conservar desaparecerá, pues solo sobrevive el más fuerte.

Si se confunde valor con precio, a la cultura y la naturaleza se les dará un valor monetario; si no se venden o si aparece un producto sustituto más barato, entonces se perderán. No hay que olvidar que el mercado no obedece a las reglas de la ética, y que la competitividad sigue las reglas del mercado.

La competitividad exacerba la explotación de los recursos y las culturas. Bajo la disculpa de la rentabilidad, su visión cortoplacista, desconoce los ciclos ecológicos, si es más rentable y hay costo oportunidad, se extrae y se utiliza ya. Su mirada egoísta descarta la preocupación por las futuras generaciones, humanas y no humanas.

Además, la competitividad ignora el enfoque ecológico en el que las cadenas tróficas muestran que la supervivencia de las especies depredadora y presa depende no solo de ambas, sino de todo el ecosistema. Ignora, también, que la viabilidad de una especie no requiere únicamente del más fuerte, ni de un macho y una hembra, requiere de un colectivo.

Y mientras para el cambio climático, la pérdida de biodiversidad, el agujero en la capa de ozono y la pobreza humana se cuenta con cifras y estudios científicos que las demuestran, la competitividad solo tiene indicadores sobre sí misma, pero no datos reales sobre sus efectos positivos en las naciones, los territorios y la naturaleza. 
Pese a contar con cifras, hoy existen escépticos respecto al cambio climático y la necesidad de hacer un cambio hacia el desarrollo sostenible; no así sobre la competitividad. Como plantea Donald Trump (2012): "El concepto de calentamiento global fue creado por y para los chinos para hacer el sector manufacturero estadounidense no competitivo"3. Las críticas que se hicieron a la frase de Trump por cuestionar el calentamiento global ponen en evidencia que incluso quienes saben la trascendencia del cambio climático, no cuestionan la necesidad implícita de la competitividad.

En este punto vale anotar que una de las críticas al desarrollo sostenible es que antepone el crecimiento económico a los pilares ambiental y sociocultural, y que sus estrategias e incentivos se basan en el mercado. Por estas razones autores como Leff (2002 y 2014), Carrizosa (2002) y Ángel y Ángel (2002) proponen la sustentabilidad.

No poner en duda la competitividad y el asumirla como el pilar central del sis tema de pensamiento moderno, además de convertirla en dogma, es peligroso. La apuesta por la lucha en la que solo sobrevive el más fuerte puede llevar a la pérdida de aquellos ecosistemas, formas de vida, culturas, conocimientos, sociedades y territorios que no sean viables bajo las reglas del mercado.

La sobrevivencia de unos pocos va de manera ineludible en contravía de la diversidad biológica y cultural; de allí que hablar de competitividad sustentable sea un oxímoron.

\section{LAS UTOPÍAS}

La idea del ser humano competitivo, egoísta y depredador por naturaleza parece tan arraigada en los imaginarios, que propuestas alternativas como la colaboración, el buen vivir y sustentabilidad son desestimadas calificándolas de utopías románticas impracticables. Sin embargo, como se verá a continuación, este juicio sobre el ser humano es ideológico, no una sentencia científica comprobada por estudios biológicos, ecológicos y antropológicos, como sostiene Riechmann (2014).

Así, por ejemplo, estudios de biología y ecología, Strandburg-Peshkin y otros (2015), muestran cómo en especies de animales con estructuras sociales jerárquicas, la toma de decisiones que afectan el grupo no es individualista. Frente al posible conflicto, emergen procesos compartidos que orientan el comportamiento colectivo, muy similares a la democracia. En relación con lo anterior, Ruiz-García (2013) afirma

Traducción del autor del tweet de Donal trump: @realDonaldTrump. (11:15am,6 nov. 2012). The concept of global warming was created by and for the Chinese in order to make U.S. manufacturing non-competitive. [Tweet Post]. 
que la cooperación entre los individuos es más importante que la competencia en todos los sistemas de animales que viven en sociedad.

De hecho, en contraposición al darwinismo social que se enfoca en la competencia y la lucha por la vida para la supervivencia del más fuerte, Lynn Margulis Citada en Riechmann (2014) plantea la idea de la vida como un fenómeno de simbiosis. Las células que componen todos los seres vivos comenzaron siendo uniones simbióticas de diferentes clases de bacterias; asimismo, elementos abióticos como el agua, el aire y minerales del suelo son comunes, en cierto modo, a todos los seres vivos, por lo que todos los habitantes de la Tierra hacen parte de una gran unidad simbiótica, según Riechmann (2014).

Riechmann (2014) plantea que las grandes transiciones evolutivas han sido el resultado de procesos de cooperación, y que en la naturaleza, aunque hay relaciones de competencia, predominan las de cooperación, colaboración y simbiosis entre los seres vivos, así como relaciones de dependencia de los elementos abióticos como el agua, el aire y los minerales. Al respecto Gudynas (2004) plantea el interrogante de si no deberían ser este tipo de relaciones las que orienten la construcción de nuevas sociedades.

Riechmann (2014) sostiene que Occidente comete uno de sus mayores fracasos al poner la competencia como el "motor" de la sociedad, a la lucha y la rivalidad de unos contra otros, como el paradigma de las relaciones humanas. Las sociedades se basan en el intercambio, no solo de bienes y servicios, también de conocimientos, pero al imponer la competencia en ese intercambio se genera la destrucción del otro, un enfrentamiento cuyo resultado será un ganador y un perdedor, sin abrir la oportunidad a intercambios para beneficios mutuos.

Como se observa, lo anterior tiene serias repercusiones en el campo sociocultural, pues derrumba la visión despiadada de la evolución basada en la competencia en que se sustenta el capitalismo económico, la competitividad y la sociedad actual.

De hecho, estudios antropológicos de Boyd y Richerson (1985) sobre la evolución muestran que la cultura hace parte de la biología; asimismo, que existen aprendizajes sociales o colectivos que se transmiten entre generaciones, los cuales juegan un papel importante en la evolución. Así, por ejemplo, la reciprocidad y la prosociabilidad son características propias de los seres humanos importantes en el proceso de selección, a lo que denominan coevolución genético-cultural.

En este sentido, Bowles y Gintis (2013, p. 1) afirman que, contrario a lo que se piensa, el ser humano no es por naturaleza egoísta, la gente coopera no solo a causa 
de intereses propios, sino también porque está genuinamente preocupada por el bienestar de los otros, trata de proteger las normas sociales y valora el comportamiento ético por sus propios motivos. Las personas, además, buscan contribuir al éxito de procesos conjuntos, que beneficien al grupo, lo que produce sentimientos de satisfacción, orgullo e, incluso, euforia.

Bowles y Gintis (2013) afirman que estos sentimientos morales se deben a que nuestros ancestros vivían en ambientes naturales y construidos en sociedad, en las que los grupos estaban predispuestos a cooperar y proteger normas éticas, con el fin de sobrevivir y expandirse. Evidencia de esto es que incluso los primeros grupos humanos actuaban de forma cooperativa y colaborativa para cazar, y compartían los resultados de la faena con los integrantes de su grupo. Aún se pueden observar acciones colaborativas de este tipo en pueblos calificados de individualistas, según Pritchard (1992).

Este comportamiento cooperativo no es exclusivo de la especie humana; sin embargo, como afirman Bowles y Gintis (2013), en el caso del homo sapiens, la cooperación se extiende más allá de parientes genealógicos, incluso extraños. Los movimientos animalistas y ecologistas muestran que este comportamiento humano vas más allá, cooperando con otras especies.

Para Bowles y Gintis (2013) hay dos tipos de comportamiento cooperativo, el primero, mutualista que hace referencia a aquel en el que existe un beneficio o costo directo para el cooperante y puede ser motivado en su totalidad por interés propio. El segundo, cuando la cooperación no se da para el beneficio de un individuo, se denomina de altruismo.

En efecto los individuos están constituidos por sus relaciones, las cuales son la base de la identidad; lo que somos se construye de forma social; las culturas solo existen en la medida que son compartidas por un grupo de personas. Como afirman Daly y Cobb (1997, p. 150) para poder sobrevivir los niños no necesitan solo de alimentos, bebidas y medicamentos, requieren de amor.

Es necesario, por tanto, abrir campo a modelos alternativos a la competencia, como la cooperación y la colaboración. La sustentabilidad hoy exige, como la llama Leff (2001), una reconstrucción ontológica y epistemológica de la naturaleza, esto es, superar el paradigma de la primacía de la competencia, la lucha entre individuos y la supervivencia del más fuerte como base para la evolución y el progreso, y superar, también el paradigma de la relación humano naturaleza occidental, hacia una no mercantil, ni comercial, mucho menos individualista, en la que la naturaleza 
no se reduce a recurso, y donde la preocupación por ella no es en función del uso, ambiente y medio ambiente humano.

Grupos indígenas y campesinos de América Latina desde sus cosmogonías, transitan esta senda. Frente al dominio del mercado global y la estructura capitalista de producción y control que amenazan a los grupos sociales y ecosistemas en todo el mundo, resurgen el tequio, el convite, la minga y la manocambiada.

Los esfuerzos de pueblos indígenas, como en el caso de Chiapas (México) para construir soluciones locales y autónomas, ofrecen alternativas para implementar sus propias estrategias hacia la sustentabilidad. De acuerdo con Barkin y Lemus (2015), estos grupos conservan gran parte de sus valores culturales y se caracterizan por la solidaridad, también por la conciencia sobre la importancia de su patrimonio y su historia; asimismo, por la construcción colectiva de su identidad y sistemas de creencias, elementos que han permitido la generación de formas únicas de organización y de dinámicas sociales, ligadas a la colaboración que, además, conducen a la justicia social y la sustentabilidad.

En Colombia, los resguardos indígenas y consejos comunitarios de afrodescendientes son formas de organización social que no obedecen al esquema de la búsqueda de competitividad y la acumulación; conceptos como propiedad difieren de la visión capitalista; de allí que se definen como territorios colectivos y que las comunidades indígenas no hablen de planes de desarrollo, sino de vida.

Desde Ecuador y Bolivia, el buen vivir hace una fuerte crítica al desarrollo y al capitalismo, ligada a un cuestionamiento de la Modernidad y su dualismo que separa al hombre y la sociedad de la naturaleza, convirtiéndola en un objeto que puede ser dominado y apropiado, como muestra Gudynas (2011).

El buen vivir plantea un nuevo horizonte, una nueva utopía, a través de la cual se intenta construir un proceso de transformación que permita reconfigurar las relaciones humanas, con la naturaleza y con el cosmos, según Crespo (2013), y de este modo, afirma Gudynas (2011), lograr aquello que la sociedad, los territorios, los pueblos y cada ser humano-colectivo, universal y particular a la vez, valora como objetivo de vida, sin generar ningún tipo de dominación sobre otro.

Aparecen también las epistemologías del Sur de De Sousa (2011), como un reclamo de quienes han sufrido opresión y discriminación por el capitalismo y el colonialismo, con sus formas de desigualdad como el valor de cambio, la propiedad individual de la tierra, el individualismo, lo material por encima de lo espiritual, entre otras. Un reclamo que busca nuevos procesos de producción, de valoración de co- 
nocimientos científicos y no científicos, y de nuevas relaciones entre diferentes tipos de conocimiento, más allá de los occidentales y eurocéntricos. Las epistemologías del sur reconocen que la diversidad es infinita; por tanto hay múltiples formas de pensar, sentir, sentir-pensar, diferentes formas de relacionarse entre humanos y con la naturaleza, más allá de la competencia, y diferentes formas de organizar la vida colectiva.

La búsqueda y el resurgir de alternativas no es exclusiva de países latinoamericanos; desde África, Murithi (2009) nos habla del ubunto como esencia del ser humano, significa ser generoso, hospitalario, amable, atento y compasivo, compartir lo que se tiene se refiere también a que la humanidad de cada individuo está ligada de forma indisoluble a la de los demás.

Además de pueblos indígenas y campesinos, Mason (2015) afirma que en países de Europa, Norteamérica y Asia, los avances en las tecnologías de información y comunicación (TIC) impulsan el cambio hacia el poscapitalismo. Gracias a las nuevas posibilidades de actividades generadoras de ingresos a partir de las redes sociales, los límites entre trabajo y tiempo libre son difusos. La forma en que el mercado y las grandes corporaciones fijan los precios se ven también afectadas por los flujos de información que existen y la posibilidad de compartirla.

Emergen nuevas formas de producción colaborativa de bienes y servicios, como el caso de Wikipedia. Se expanden también formas alternativas de propiedad, préstamos, contratos, como lo que Mason (2015) llama la economía del compartir. Incluso el concepto de empresa se ve cuestionado con la aparición y uso masivo de apps para colaborar y para compartir bienes y servicios; así, por ejemplo, Airbnb, Couchsurfer y Carpool, en los que son personas y no empresas las que prestan servicios.

Por otro lado, casas de software con tradición en el mercado como Office y Adobe, hoy incluyen la opción compartir en sus programas y se caracterizan por la edición colaborativa, cambios ocasionados no solo por las redes sociales, también por las alternativas de software libre y gratuito como los ofrecidos por Linux y Google.

Estas alternativas "utópicas" ofrecen rutas de escape a la visión de una sociedad en competencia. Mientras la competitividad se basa en la muerte del adversario, la colaboración busca construir con los otros, incluida toda la naturaleza, o lo que en palabras de Leff (2001, 2014), es la ética de la vida llamada sustentabilidad.

Así como la competencia es solo una de varias formas de relación entre especies, el capitalismo y la búsqueda del crecimiento económico son formas de relacionarse que caracterizan a ciertos grupos sociales. De allí que el posdesarrollo, el buen 
vivir, el ubuntu y las epistemologías del Sur no tratan de abolir la visión de desarrollo y competitividad de todo el planeta, para imponer una nueva doctrina, tampoco pretenden convertirse en dogmas. Tratan de reconocer la diversidad de formas de pensamiento, cosmogonías y economías de los pueblos.

\section{CONCLUSIONES}

La Modernidad, su reduccionismo y su mirada que separa al hombre de la naturaleza, junto con el capitalismo, la vieja idea de la evolución a partir de la competencia y la supervivencia del más fuerte, así como el imaginario económico de un hombre egoísta son la génesis de la competitividad.

La competitividad es en la actualidad el imperativo incuestionable que domina la sociedad y la toma de decisiones, lo que ha llevado a que los gobiernos y las corporaciones, así como la salud, los ecosistemas y la educación, hoy estén en la carrera hacia la ventaja competitiva.

Como resultado de la carrera hacia la competitividad, el antropocentrismo dio paso al organocentrismo; de esta manera la creación de empresas y personas jurídicas se convirtió en requisito para el desarrollo, pues solo estas agregan valor. La libre competencia pasó a ser un derecho, y no permitirla es un delito, haciendo que las organizaciones/empresas sean más importantes que los seres humanos y los Estados.

Sin bases teóricas, ni citas, sin conceptos ni metodologías claros y pasando por encima de la ética, el porterismo a partir de análisis ex post de un grupo de empresas, logró constituirse en el dogma que domina las escuelas de administración y modelos de gobernanza.

El dogma de la competitividad va en contravía de la diversidad biológica y cultural; por lo tanto, pone en peligro ecosistemas, formas de vida, modos de pensamiento, culturas, cosmogonías y sociedades que no sean viables bajo las reglas del mercado.

Ni la evolución es el resultado exclusivo de la competencia y la lucha por la supervivencia del más fuerte, ni el ser humano es egoísta por naturaleza. Al contrario, las culturas y la vida son el resultado de variados tipos de relaciones como la colaboración, la cooperación, la simbiosis, así como la codependencia de elementos abióticos.

Nuevos caminos aparecen, el poscapitalismo, las epistemologías del Sur y el buen vivir son algunas utopías que buscan nuevas formas de relacionarnos entre humanos y con la naturaleza, más allá de la competencia y el mercado, nuevas metas más allá del desarrollo, apuestas por la vida, como la sustentabilidad. 
El dogma de la competitividad frente a la utopía de la sustentabilidad: análisis crítico del ethos desarrollista y economicista

\section{BIBLIOGRAFÍA}

Ángel, Augusto y Ángel, Felipe (2002). La ética de la tierra. Ética y medio ambiente, p. 12-26. En: Leff, E. (Coord.). Ética, vida y sustentabilidad. PNUMA: México, D.F., 342p.

Aktouf, Omar (2008). Gobernancia y pensamiento estratégico: una crítica a Michael Porter. En: Administración y Organizaciones. Desarrollo del Pensamiento Administrativo y Organizacional. Décimo Aniversario. Año 11, No. 21, diciembre, p. 157-183.

Banco Mundial (2011). Brecha de pobreza a \$1,90 por día (2011 PPA). Banco Mundial.

Barkin, David y Lemus, Blanca (2015). Construyendo mundos pos-capitalistas. En: Cultura y representaciones sociales. Año 10, No. 19, septiembre, México, DF., p. 26-60.

Beschorner, Thomas (2013). Creating Shared Value: The One-Trick Pony Approach. En: Business Ethics Journal Review, Vol. 1, No. 17, p. 106-112. Doi.org/10.12747/bejr2013.01.17.

Boyd, Robert y Richerson, Peter (1985). Culture and the Evolutionary Process. The University of Chicago Press, Chicago, 339p.

Bowles, Samuel y Gintis, Herbert (2013). A Cooperative Species: Human Reciprocity and Its Evolution. Princeton University Press, ISBN: 9780691158167, 280p.

Carrizosa, Julio (2002). Hacia nuevas economías. Mímesis, hedonismo, violencia y sustentabilidad, p. 43-50. En: Leff, E. (Coord.). Ética, vida y sustentabilidad. PNUMA: México, D.F., 342p.

Colvin, Geoff (2012). There's no quit in Michael Porter. En: Fortune Magazin, Octubre 15, 2012, 9:00 AM EDT.

Crespo, Juan (2013). El buen vivir: del Sumak Kawsay y Suma Qamaña a las constituciones del buen vivir. Contradicciones y desafío entre la teoría y la práctica. Tesis: Máster en Globalización y Desarrollo, Hegoa, UPV/EHU, Bilbao, España, 128p.

Daly, Herman y Cobb, John (1997). Para el bien común: reorientando la economía hacia la comunidad, el ambiente y un futuro sostenible. México: Fondo de Cultura Economica, 467p.

Daly, Herman (2010). Foreword, p. ix-xiv. En: Berry, W. What matters?. Economics for a renewed Commonwealth. Berkeley, USA, Counterpoint, First Edition edition, 256p.

De Sousa Santos, Boaventura (2011). Introducción: las epistemologías del Sur, p. 9-22. En: Formas-Otras. Saber, nombrar, narrar, hacer. IV Training Seminar de jóvenes investigadores en Dinámicas Interculturales, Barcelona: CIDOB Ediciones, 242p.

DNP -Departamento Nacional de Planeación - (1995). El salto social: plan nacional de desarrollo: ley de inversiones, 1994-1998. Presidencia de la República, Departamento Nacional de Planeación, 368p.

DNP -Departamento Nacional de Planeación- (2007). Plan Nacional de Desarrollo Estado Comunitario: desarrollo para todos. Presidencia de la República, Departamento Nacional de Planeación, Tomo I, 440p.

Escobar, Arturo (1998). La Invención del Tercer Mundo: Construcción y Deconstrucción del Desarrollo. Colombia: Editorial Norma, 475p. 
Escobar, Arturo (2014). Sentipensar con la tierra. Nuevas lecturas sobre desarrollo, territorio y diferencia. Medellín: Ediciones UNAULA, colección Pensamiento vivo, 184p.

Eschenhagen, María Luisa y Maldonado, Carlos Eduardo (Edit.) (2014). Un viaje por las alternativas del desarrollo. Perspectivas y propuestas teóricas. Bogotá; Universidad Pontificia Bolivariana y Universidad el Rosario, 164p.

Esteva, Gustavo (1996). Desarrollo, p. 52-78. En: Sachs, W. (editor), Diccionario del desarrollo. Una guía del conocimiento como poder, PRATEC, Perú, (primera edición en inglés en 1992), 399p.

Esteva, Gustavo (2014). Commoning in the new society. En: Community Development Journal. Vol. 49 No. S1, enero, p. i144-i159. Doi:10.1093/cdj/bsu016.

Foucault, Michel (1999). Arqueología del saber. México: Siglo XXI editors, 368p.

Gudynas, Eduardo (2011). Buen vivir: germinando alternativas al desarrollo. En: América Latina en movimiento, No. 462, febrero, Año xxxv, II época, p 1-20.

Gudynas, Eduardo (2015). La derecha y la izquierda no entienden la naturaleza. En: Diario La Razón, Suplementos, Animal Político: Raza política, agosto 23, La Paz, Bolivia.

Gudynas, Eduardo (2004). Ecología, Economía y Ética del Desarrollo Sostenible. Montevideo: CLAES, Centro Latino Americano de Ecología Social y D3E, Montevideo, 5ta. Edición, 264p.

Gunderson, Lance y Holling, C.S. (Edits) (2002). Panarchy: Understanding transformations in human and natural systems. Washington: Island Press, 448p.

IPCC -Intergovernmental Panel on Climate Change - (2015). Summary for Policymakers, p. 18-49. En: Pachauri, R.K. y MeyerClimate, L. (Edits) Change 2014 Synthesis Report. Intergovernmental Panel on Climate Change, Geneva, Switzerland, IPCC, 169p.

Krugman, Paul (1993). Competitiveness: A Dangerous Obsession. En: Foreign Affairs, Vol. 73, No. 2, p. 28-44.

Lander, Edgardo (2005). La ciencia neoliberal. En: Revista Venezolana de Economía y Ciencias Sociales. Vol.11 No. 2, Caracas, mayo-agosto, p. 35-70.

Leff, Enrique (2001). Espacio, lugar y tiempo. La reapropiación social de la naturaleza y la construcción local de la racionalidad ambiental. En: Nueva Sociedad, No.175, septiembre-octubre, p. 28-42.

Leff, Enrique (2002). Ética por la vida. Elogio de la voluntad de poder, p. 288-314. En: Leff, E. (Coord.). Ética, vida y sustentabilidad. PNUMA: México, D.F., 342p.

Leff, Enrique (2004). Racionalidad ambiental: la reapropiación social de la naturaleza. Siglo XXI editores: México, D.F., 536p.

Leff, Enrique (2014). La apuesta por la vida, imaginación sociológica e imaginarios sociales en los territorios ambientales del Sur. Brasil, Vozes Editora, 378p.

Martínez-Alier, Joan y Schlüpmann, Klaus (1991). La ecología y la economía. Fondo de Cultura Económica, 367p.

Mason, Paul (2015). PostCapitalism: A Guide to Our Future. New York, Pinguin, 368p. 
El dogma de la competitividad frente a la utopía de la sustentabilidad: análisis crítico del ethos desarrollista y economicista

Max-Neef, Manfred (1994). Desarrollo a escala humana. Conceptos, aplicaciones y algunas reflexiones. Barcelona: Editorial Icaria S.A., 148p.

Millennium Ecosystem Assessment (2005). Ecosystems and Human Well-being: Biodiversity Synthesis. World Resources Institute, Washington, DC., 100p.

Murithi, Tim. (2009) An African perspective on peace education: ubuntu lessons in reconciliation. En: International Review of Education, Vol. 55, No. 2, p. 221-233. Doi: 10.1007/s11159-009_ 9129-0.

Oxfam (2014). Gobernar para las élites: Secuestro democrático y desigualdad económica. Informe de Oxfam No. 178, 20 de enero, 34p.

Porter, Michael (1979). How Competitive Forces Shape Strategy. En: Harvard Business Review, Vol. 57, No. 2 , marzo-abril, p.137-145.

Porter, Michael (1980). Competitive Strategy: Techniques for Analyzing Industries and Competitors. New York: Free Press, 397p.

Porter, Michael (1985). Competitive Advantage: Creating and Sustaining Superior Performance. New York: Free Press, 592p.

Porter, Michael (1990). The Competitive Advantage of Nations. New York: Free Press, 892p.

Porter, Michael y Kramer, Mark (2011). Creating Shared Value. En: Harvard Business Review, Vol. 89, No. $1 / 2$, p. 62-77

Pritchard, Evans (1992). Los Nuer. 2a edición, traducción de Carlos Manzano, Barcelona: Editorial, Anagrama.

Riechmann, Jorge (2014). Hacia un ecologismo epicúreo, p. 399-433. En: Gian Carlo Delgado Ramos (coord.). Buena vida, buen vivir: Imaginarios alternativos para el bien común de la humanidad. Colección Debate y Reflexión, CEIICH-UNAM, México DF., ISBN: 978-607-025402-4, 443p.

Ruiz-García, Manuel (2013). Diez lecciones de Darwin para los humanistas: el legado de la evolución. En: Revista Arcadía, 18 de marzo.

Sandel, Michael (2014). Hay una profunda frustración con la democracia. Revista Semana, septiembre 13.

Strandburg-Peshkin, Ariana; Farine, Damien; Couzin, Iain y Crofoot, Margaret (2015). Shared decision-making drives collective movement in wild baboons. En: Science, Vol. 348, No. 6241, 19 de junio, p. 1358-1361. Doi:10.1126/science.aaa5099.

Schwab, Klaus (2014). The Global Competitiveness Report 2014-2015. World Economic Forum (WEF), Geneva, 565p.

Unesco (2003). Vitalidad y peligro de desaparición de las lenguas. Grupo especial de expertos sobre las lenguas en peligro convocado por la Unesco. Paris, 26p.

von Bertalanffy, Ludwig (1969). General System Theory: Foundations, Development, Applications (Revised Edition). New York: Penguin University Books, 296p. 
